\title{
PERCEIVED POSTPARTUM STRESS AND COPING STRATEGIES AMONG POSTNATAL MOTHERS AT AIMS, KOCHI
}

\author{
RACHEL MARGRET MATHEW ${ }^{1}$, ANJU PHILIP T ${ }^{1 *}$, SREEJAMOL MG ${ }^{2}$
}

${ }^{1}$ Department of Obstetrics and Gynecologic Nursing, Amrita College of Nursing, Amrita University, Kochi, India. ${ }^{2}$ Department of Mental Health Nursing, Amrita College of Nursing, Amrita University, Kochi, India. Email: anjuphilip@aims.amrita.edu

Received: 13 July 2017, Revised and Accepted: 17 August 2017

\section{ABSTRACT}

Objectives: The present study aimed to identify the perceived postpartum stress among postnatal mothers, identify coping strategies adopted by postnatal mothers, find out correlation between the level of perceived postpartum stress and coping strategies among postnatal mothers and find out the association between the level of perceived postpartum stress and demographic variables.

Methods: A quantitative descriptive study was conducted among 100 postnatal mothers. Convenience sampling technique was used. Hung postpartum stress scale and coping strategies inventory short form were used for the assessment of postpartum stress and coping strategies.

Results: Among the 100 participants, $63 \%$ of the postnatal mothers had mild stress, 33\% had moderate stress, and only $4 \%$ had severe stress. Majority of the mothers were used problem-focused engagement as a coping strategy. There was a positive correlation found between the level of perceived postpartum stress and coping strategies such as emotion-focused engagement and emotion-focused disengagement. There was significant association found between the level of perceived postpartum stress and demographic variables such as age, education, length of marriage, status of pregnancy, method of baby feeding, pregnancy events, intrapartum events, birth weight of baby, child birth experience, status of newborn, and postpartum events.

Conclusion: The high proportion and severity of postpartum stress observed among this study group proves that postpartum stress is common and cannot be ignored.

Keywords: Postpartum stress, Coping strategies, Postnatal mothers.

(c) 2017 The Authors. Published by Innovare Academic Sciences Pvt Ltd. This is an open access article under the CC BY license (http://creativecommons. org/licenses/by/4. 0/) DOI: http://dx.doi.org/10.22159/ajpcr.2017.v10i12.21257

\section{INTRODUCTION}

Postpartum is the period begins following childbirth and lasts for approximately 6 weeks during which the body changes into the prepregnant state [1]. Postpartum stress is defined as a constraining force produced by postpartum stressors (Hung 2001). These are described as conditions of change demand or structural constraints that are occurring or existing within 6 weeks of delivery. In addition to general stress, women commonly experience postpartum stress [2]. To cope up with these stress factors, mothers may adopt coping strategies. Coping strategies refer to the thought and action used by the postnatal mother in terms of self-control, acceptance of reality, and problem-solving measures to alleviate the stress after childbirth [3].

Postnatal period is the period with increased vulnerability to psychiatric illness, if the mother fails to adopt positive coping strategies. Postpartum period is associated with intense physical and emotional changes leading to anxiety [4] and mood disturbances. There are three degrees of postpartum mood disorders, i.e., "baby blues," postpartum depression (PPD) [5], and postpartum psychosis. Postpartum blues, otherwise "baby blues," are comparatively milder in nature and are the most common one, where postpartum psychosis is the most severe one.

Patil [6] conducted a descriptive study to assess the level of stress and coping strategies among 40 postnatal mothers at Karad, India. The results showed that $70 \%$ of mothers had moderate stress and $30 \%$ had severe stress. While assessing the coping strategies, $87.5 \%$ of mothers were using average level of coping measures, and $12.5 \%$ were using good coping measures.
A follow-up study was conducted by Blasio and Iinio (2002) in Italy to investigate whether postpartum stress symptoms may persist through time. Among 36 mothers, the findings showed that $22.2 \%$ of the women showed post-traumatic stress symptoms both after delivery and 18 months later. Moreover, $16.7 \%$ of women showed post-traumatic stress symptoms only after delivery [7].

It is evident that postpartum stress is a contributing factor for PPD and it is a widespread chronic physical and psychological illness but is treatable and preventable.

The purpose of the study is to (1) identify the perceived postpartum stress among postnatal mothers, (2) identify coping strategies adopted by postnatal mothers, (3) find out correlation between the level of perceived postpartum stress and coping strategies among postnatal mothers, and to (4) find out association between the level of perceived postpartum stress and demographic variables.

\section{METHODS}

A quantitative approach with the descriptive design [8] was used to conduct the study in the immunization clinic of Pediatric Outpatient Department of AIMS, Kochi, which is a multispecialty teaching hospital in South India. The data were collected using convenient sampling technique from 100 postnatal mothers. Postnatal mothers with live baby, at $6^{\text {th }}$ week of postpartum, willing to participate in the study were included in the study. Postnatal mothers with more than one newborn baby and having the previous history of psychiatric illness were excluded from the study. 
Data were collected from $22^{\text {nd }}$ October 2016 to $30^{\text {th }}$ December 2016 after obtaining ethical clearance from an Institutional Ethical Committee of AIMS, Kochi. A detailed explanation was given to the participants, and the participation was based on willingness. Informed consent was obtained from all the participants. A semi-structured interview was Used to collect background, demographic and clinical variables. Hung postpartum stress scale was used to assess the level of stress [9]. coping strategies inventory short form is a 5-point Likert scale used to assess the different ways in which people responded to stress and was developed by Addison et al. [10] data were analyzed using descriptive and inferential statistics. The sample characteristics were described using frequency and percentage. Pearson's correlation coefficient was used to find out the correlation between the level of perceived postpartum stress and coping strategies. Chi-square test is used to find out the association between the levels of perceived postpartum stress with selected demographic variables among postnatal mothers.

\section{RESULTS}

\section{Section 1: Sample characteristics}

Among the 100 postnatal mothers, majority (72\%) were in the age group of $21-29$ years, and $52 \%$ were graduates. Most of them (76\%) were employed and $70 \%$ are from nuclear family. Only $41 \%$ had duration of married life, more than 4 years. Majority (68\%) had planned pregnancy, but $55 \%$ of postnatal mothers were primipara. Around half of them (53\%) underwent cesarean section. More than half of the mothers $(55 \%)$ had a female child and $78 \%$ of baby's birth weight is more than $2.5 \mathrm{Kg}$. Most of the mothers (69\%) adopted breast feeding as the feeding pattern. Most of them (87\%) got satisfied by childbirth experience. Most of the (81\%) mothers had healthy newborn. Only a few (23\%) mothers had significant events during the antenatal period, but (21\%) had a high risk during intrapartum. And a very few (11\%) had postpartum events.

Section 2: Perceived postpartum stress among postnatal mothers Perceived postpartum stress was mild among (63\%) postnatal mothers. However, none of them were experienced eustress and extreme stress. Rest of them had moderate stress (33\%), and only a few had severe stress (4\%) (Fig. 1).

Fig. 2 shows most of the postnatal mothers (55\%) had mild stress on attainment of maternal role, $(40 \%)$ had a moderate level of stress and a very few (3\%) had extreme stress, and severe stress $(2 \%)$.

More than half of the postnatal mothers $61 \%$ had mild stress on negative body changes and $23 \%$ had moderate stress, very few $8 \%$ had severe stress. Moreover, $8 \%$ of them were reported eustress (Fig. 3).

While exploring stress related to lack of social support majority $73 \%$ of mothers had mild stress and $13 \%$ had moderate stress, only $1 \%$ had severe stress due to lack of social support. Few mothers were reported eustress (13\%) (Fig. 4).

Section 3: Coping strategies adopted by postnatal mothers

From Table 1, it is evident that the coping strategies adopted by postnatal mothers in problem-focused engagement with a mean of 12.22 (ranged between 5 and 20), mean score percentage 61.1 and standard deviation 3.56. Problem-focused disengagement was used by the postnatal mothers with a mean score of 11.52, (ranged between 4 and 19), mean score percentage 57.6, and with a standard deviation of 3.53. Postnatal mothers used emotion focused engagement and disengagement with mean scores 11.48 (ranged between 4 and 20) and 9.41 (ranged between 4 and 20), mean score percentages 57.4 and 47.05 , and standard deviation of 3.86 and 3.71 correspondingly.

Section 4: Correlation between the level of perceived postpartum stress and coping strategies among postnatal mothers

Table 2 summarizes that statistically significant positive correlation was found between the level of perceived postpartum stress and coping strategies in emotion-focused engagement $(r=0.219, p=0.029)$ and there was statistically highly significant positive correlation was found

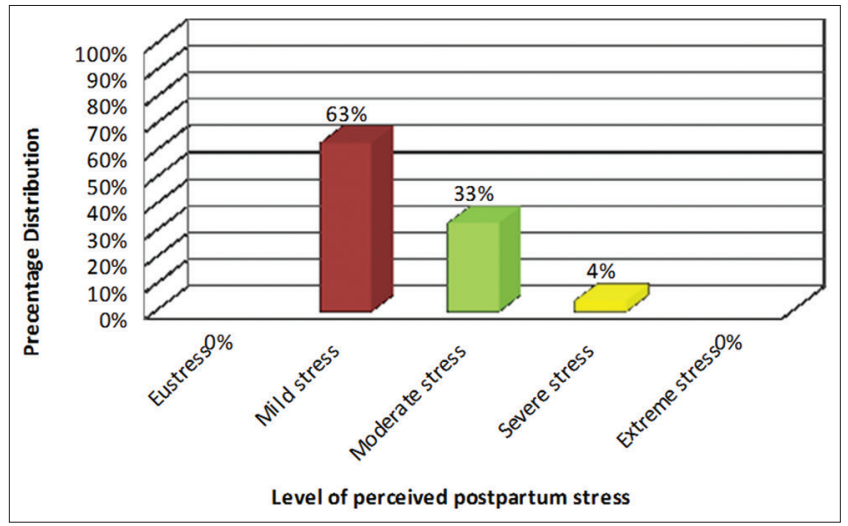

Fig. 1: Distribution of subjects based on the level of perceived postpartum stress $n=100$

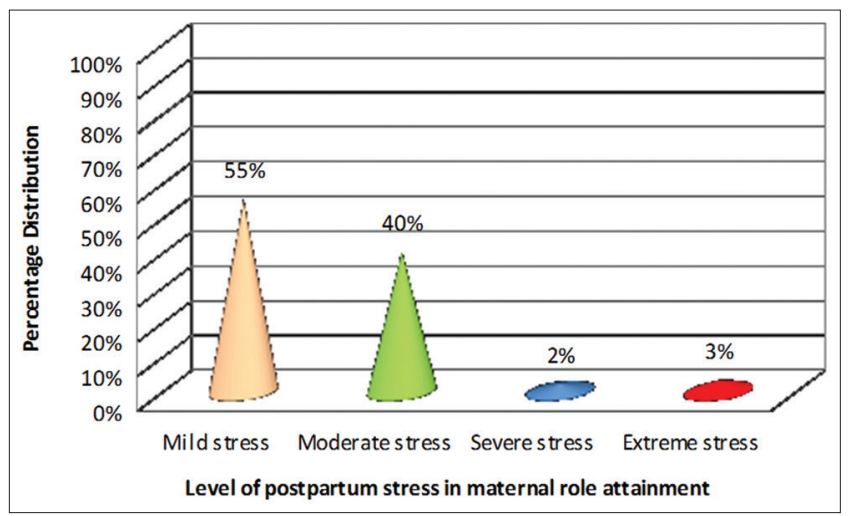

Fig. 2: Distribution of subjects based on level of perceived postpartum stress in maternal role attainment $n=100$

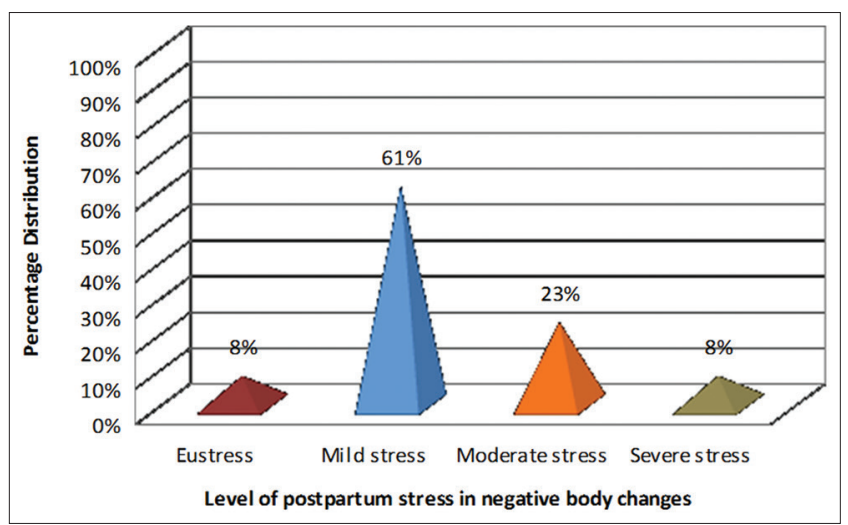

Fig. 3: Distribution of subjects based on level of perceived postpartum stress in negative body change $n=100$

between the level of perceived postpartum stress and coping strategies in emotion-focused disengagement $(r=0.532, \mathrm{p} \leq 0.001)$.

Section 5: Association between the level of perceived postpartum stress and demographic variables

Statistically significant association was found between perceived postpartum stress and sociodemographic variables such as age $\left(\chi^{2}=10.714, \mathrm{p}=0.007\right)$, education status $\left(\chi^{2}=9.274, \mathrm{p}=0.010\right)$, length of marriage $\left(\chi^{2}=5.996, p=0.054\right)$, status of pregnancy $\left(\chi^{2}=8.854, p=0.015\right)$, method of baby feeding $\left(\chi^{2}=10.714, p=0.005\right)$, pregnancy events $\left(\chi^{2}=13.949, \mathrm{p}=0.002\right)$, and intrapartum events $\left(\chi^{2}=15.675, \mathrm{p}=0.001\right)$ and there was statistical highly significant association with baby's 
Table 1: Maximum score, mean score, standard deviation, range and mean score percentage of coping strategies adopted by postnatal mothers $n=100$

\begin{tabular}{llllll}
\hline Category of coping strategies & Maximum score & Mean score & Standard deviation & Range & Mean score percentage (\%) \\
\hline Problem-focused engagement & 20 & 12.22 & 3.56 & $5-20$ & 61.1 \\
Problem-focused disengagement & 20 & 11.52 & 3.53 & $4-19$ & 57.6 \\
Emotion-focused Engagement & 20 & 11.48 & 3.86 & $4-20$ & 57.4 \\
Emotion-focused disengagement & 20 & 9.41 & 3.71 & $4-20$ & 47.05 \\
\hline
\end{tabular}

Table 2: Correlation between the level of perceived postpartum stress and coping strategies $n=100$

\begin{tabular}{lll}
\hline Coping strategy & $\begin{array}{l}\text { Perceived } \\
\text { postpartum stress }\end{array}$ & p value \\
\cline { 2 - 3 } & $\begin{array}{l}\text { Correlation } \\
\text { coefficient }\end{array}$ & \\
& 0.174 & 0.083 \\
Problem-focused engagement & 0.124 & 0.219 \\
Problem-focused disengagement & 0.219 & $0.029^{*}$ \\
Emotion-focused engagement & 0.532 & $<0.001^{* *}$ \\
Emotion-focused disengagement & 0.532 & \\
\hline
\end{tabular}

${ }^{*} \mathrm{p}<0.05,{ }^{* *} \mathrm{p}<0.001$

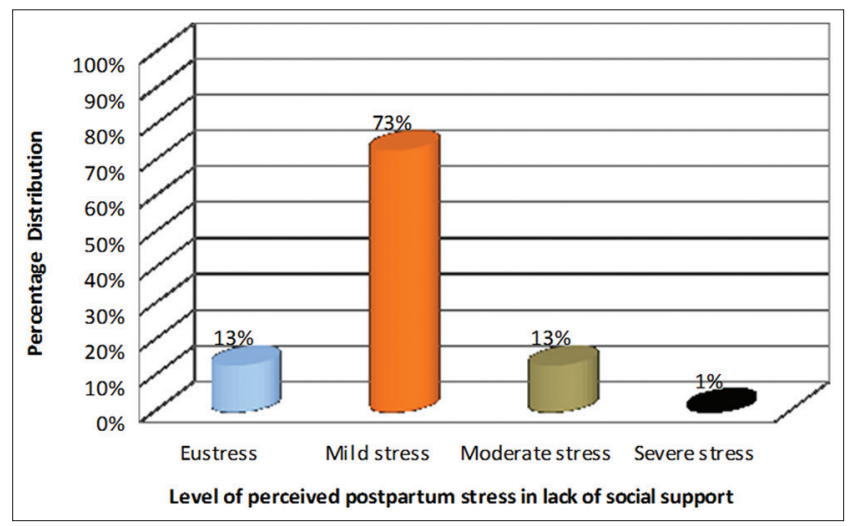

Fig. 4: Distribution of subjects based on the level of perceived postpartum stress in lack of social support $n=100$

birth weight $\left(\chi^{2}=47.917, \mathrm{p}<0.001\right)$, childbirth experience $\left(\chi^{2}=27.885\right.$, $\mathrm{p}<0.001)$, status of newborn $\left(\chi^{2}=17.763, \mathrm{p}<0.001\right)$, and postpartum events $\left(\chi^{2}=33.712, \mathrm{p}<0.001\right)$.

\section{DISCUSSION}

The findings of the study show that among 100 postnatal mothers $63 \%$ were had mild postpartum stress, $33 \%$ had moderate stress, and only $4 \%$ had severe stress. All the mothers were reported to have different levels of stress. The present study finding is in congruent with the results of the study conducted by Naganandini [11], among 60 primi mothers on stress at Salem, Tamil Nadu, and the results of the study show that $74 \%$ and $97 \%$ of mothers in control and experimental group had a moderate level of stress. After teaching, $80 \%$ of mothers in the experimental group had mild stress, and $23 \%$ of mothers in control group had mild stress, and $63 \%$ of them had moderate stress. Most of the studies in literature search show the importance of health teaching and awareness programs during antenatal period may reduce the stress among mothers.

In this study, all the 100 mothers were reported different levels of stress related to maternal role attainment since it is critical period in women's life because responsibility of women will increase after motherhood. Analyzing the stress of mothers in negative body changes and lack of social support noticed that majority of the postnatal mothers had stress at various levels, but none of them reported extreme stress.
Among the 100 mothers, only one mother had severe stress due to lack of social support. It shows the family and society giving support to mothers after delivery. Support from others will reduce the stress.

While describing the coping strategies adopted by the postnatal mothers, the majority of them were adopted problem-focused engagement type of coping strategy with a mean score of $61.1 \%$. Lakshmi and Padmaja [12], conducted a study among 100 mothers, to assess the level of stress and coping strategies among mothers of neonates at, Tirupati shows that among 100 mothers 30\% mothers had poor coping, $47 \%$ mothers had moderate coping and $23 \%$ mothers had good coping. Mothers need to educate about coping strategies such as praying, reading books, and expressing emotions to overcome the stress after delivery.

Positive correlation was found between the level of perceived postpartum stress and coping strategies such as emotion-focused engagement $(\mathrm{r}=0.219, \mathrm{p}=0.029)$ and emotion-focused disengagement $(\mathrm{r}=0.532, \mathrm{p} \leq 0.001)$.

In this present study, there was statistically significant association was found between perceived postpartum stress and variables such as age, education, length of marriage, status of pregnancy, method of baby feeding, pregnancy events, intrapartum events, baby's birth weight, childbirth experience, status of newborn, and postpartum events. Clara Gronowitz and Helena Henrysson [13] conducted a study at Thailand, among 160 women on stress, social support and health status among postpartum women. The perceived stress was low among mothers, but the study result shows good social support especially from partners and parents.

\section{CONCLUSION}

Postnatal mothers are suffering from perceived postpartum stress in attaining maternal role, dealing with negative body changes and in lack of social support. And they use different types of coping strategies such as problem-focused engagement, problem-focused disengagement, emotion-focused engagement, and emotion-focused disengagement. Hence, it is evident that there is a need to address the problem and give proper guidance to the postnatal mothers. Various types of relaxation techniques and stress management programs can be organized for them before they are leaving the hospital.

\section{ACKNOWLEDGMENT}

We would like to extend our sincere thanks to our chancellor Mata Amritanandamayi Devi, for providing us an opportunity to conduct the same.

\section{REFERENCES}

1. Dutta DC. Text book of Obstetrics Including Perinotology and Contraception. $6^{\text {th }}$ ed. Calcutta: New Central Book Agency (P) LTD; 2004. p. 145

2. Hung $\mathrm{CH}$. Measuring postpartum stress: Methodological issues in nursing research. J Adv Nur 2004;50(4):417-418.

3. Simkin P. Birth trauma: Definition and statistics. Prevention and treatment of traumatic childbirth. Am J Obset 2008;10(2):189-203. Available from: http://www.pattch.org/resource-guide/traumaticbirths-and-ptsd-definition-and-statistics/.

4. Abhilash T. Assessment of psychological stressors of depression and 
anxiety using depression anxiety stress scale-21 in South Indian healthy volunteers. Int J Pharm Pharm Sci 2016;8(5):288-295. Available from: https://www.innovareacademics.in/journals/index.php/ijpps/article/ view/11212/5212.

5. Jamal MA. Factors affecting postpartum depression among women of the UAE and Oman. Int J Pharm Pharm Sci 2015;7(7):231-233. Available from: https:/www.innovareacademics.in/journals/index.php/ ijpps/article/view/6121.

6. Patil S. Level of stress and coping strategies seen among parents of neonates. Int J Sci Res 2014;3(4):579-85.

7. HeronJ, O' Connor TG, Evans J, Golding J, Glover V. The course of anxiety and depression through pregnancy and the postpartum in a community sample. J Affect Disorders 2004;80(1):65-73. Available from: http://www.sciencedirect.com/science/article/pii/ S0165032703002064.

8. Joseph T, Sunil M, Reji V. Assessment of the lifestyle related risk factors for cardiovascular diseases among adolescents. Indian J Public Health Res Dev 2016;7(2):97-102.

9. Hung $\mathrm{CH}$. The hung postpartum stress scale. J Nurs Scholarsh
2007;39(1):1-4.

10. Addison CC, Campbell-Jenkins BW, Sarpong DF, Kibler J, Singh M, Dubbert $\mathrm{P}$, et al. Psychometric evaluation of a coping strategies inventory short-form (CSI-SF) in the Jackson heart study cohort. Int $\mathrm{J}$ Environ Res Public Health 2007;4(4):289-95.

11. Naganandini R. Effectiveness of structured stress management, module on stress of primi mothers during, early postnatal period in a selected private hospital, Salem, Tamil Nadu. Asian J Nurs Educ Res 2012;2(4):220-221. Available from: http://www.anvpublication.org/ ajner.html.

12. Lakshmi R, Padmaja A. A study to assess the level of stress and coping strategies among mothers of neonates admitted in neonatal intensive care unit at S.V.R.R.G.G.H. Tirupati. J Nur Midwifery Matern 2016;2(3):151-154.

13. Gronowitz C, Henrysson H. Stress, Social Support and Health Status among Postpartum Women in an Urban and a Rural Area of Thailand. Department of Public Health and Caring Sciences, Section of Caring Sciences; 2009. p. 1-33. Available from: https://www.diva-portal.org/ smash/get/diva2:285973/FULLTEXT01 